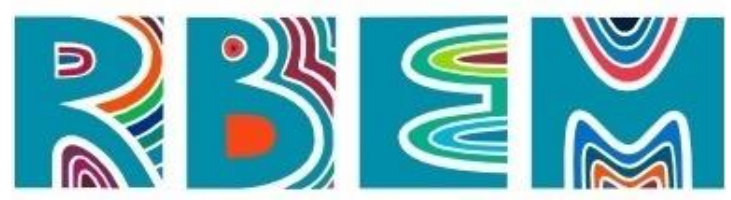

REVISTA BAIANA dE EDUCAÇÃo MATEMÁtICA

\author{
ARTIGO \\ dol https://doi.org/10.47207/rbem.v1i.10311
}

\title{
Avaliação no Ensino Remoto de Matemática: analisando categorias de respostas
}

\author{
LIMA, Daniel de Oliveira \\ Escola SESC de Ensino Médio. Mestre em Matemática pela Universidade Federal do Rio de Janeiro (UFRJ). \\ Doutorando em Ensino de Matemática pelo PEMAT/UFRJ. \\ ORCID: https://orcid.org/0000-0003-4565-3526. E-mail: danielprof2006@gmail.com.
}

\author{
NASSER, Lilian \\ Programa de Pós-graduação em Ensino de Matemática (PEMAT/UFRJ). Doutora em Educação Matemática pela \\ University of London. \\ ORCID: https://orcid.org/0000-0001-6050-4807. E-mail: lnasser.mat@gmail.com.
}

\begin{abstract}
Resumo: Diante da pandemia, em 2020, as aulas presenciais foram suspensas e as escolas tiveram que adotar um modelo que atendesse ao isolamento social e que permitisse a continuidade das aulas. Algumas escolas adotaram o Ensino Remoto Emergencial (ERE), outras criaram uma estrutura similar ao ensino à distância (EAD). Essas adaptações geraram outros dilemas sobre como seria o ensino e, consequentemente, como seria avaliar nestes modelos de ensino. Este trabalho relata a experiência de avaliação com três turmas da $2^{\mathrm{a}}$ série, na Escola SESC de Ensino Médio (ESEM), que adotou o ERE, a partir de uma situação problema, estruturada no ambiente de aprendizagem com referências à realidade. $\mathrm{O}$ modelo usado foi uma pesquisa, que tinha como objetivo promover uma maior reflexão e compreensão sobre a importância da aplicação da função exponencial na análise do comportamento da infecção pelo vírus. Os alunos tinham que explicar a diferença entre as funções exponencial, linear e quadrática, a partir de informações de cunho matemático disponíveis num texto que deveria ser acessado por um link fornecido. Além disso, eles tinham que acessar outro material, para entender alguns conceitos relacionados ao COVID 19, como a taxa de contágio, velocidade de transmissão, e como esses conceitos (ou alguns deles) se relacionam com o modelo matemático estudado, a Função Exponencial. Usando essas produções, foram categorizadas e analisadas as respostas dos 45 alunos em relação à aprendizagem de funções exponenciais. Esta experiência indica que é possível ampliar o processo de avaliação usando as tecnologias digitais.
\end{abstract}

Palavras chave: Avaliação. Ensino Remoto. Função Exponencial.

\section{Evaluation in Remote Mathematics Teaching: analyzing categories of answers}

\begin{abstract}
Ahead of the pandemic, in 2020, the usual classroom teaching had been suspended and the schools had to adopt a model that took care of to the social isolation and that allowed the continuity of the lessons. Some schools had adopted the RemoteEmergencialTeaching (RET), others had created a similar structure to long-distance education.These adaptations had generated other dilemmas on how it would be to teach and, consequently, how it would be to evaluate in these models of education. This work reports the experience of evaluation with three classes of the $2^{\text {nd }}$ year from the Escola SESC de Ensino Médio (ESEM), which has adopted the RET, based on a situation problem, structuralized in the
\end{abstract}




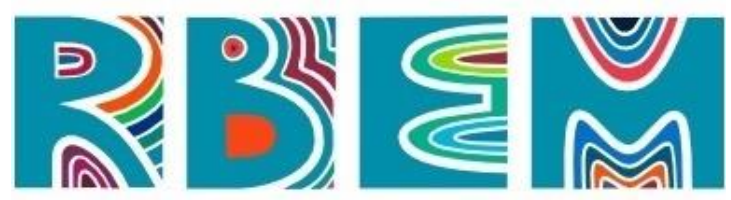

REVISTA BAIANA DE EDUCAÇÃO MATEMÁTICA

environment of learning with references to the reality.The used model was a research, which had the objective to promote a bigger reflection and understanding on the importance of the application of the exponential function in the analysis of the behavior of the infection for the virus. The students had to explain the difference between the exponential, linear and quadraticfunctions, from available mathematical information in a text that must be accessed through one link supplied. Moreover, they had to access another material, to understand some concepts related to COVID 19, as the tax of infection, speed of transmission, and as these concepts (or some of them) are related with the studied mathematical model, the Exponential Function. Using these productions, the answers of the 45 pupils in relation to the learning of exponential functions had been categorized and analyzed. This experience indicates that it is possible to extend the evaluation process using the digital technologies.

Keywords: Evaluation. Remote education. Exponential function.

\section{Evaluación en Enseñanza Remota de las Matemáticas: analizar categorías de respuestas}

Resumen: Delante del pandemic, en 2020, las lecciones reales habían sido suspendidas y las escuelas habían tenido eso para adoptar un modelo que llevaron cuidado del aislamiento social y que no prohibió a continuidad de las lecciones. Algunas escuelas habían adoptado Educatión Remota de Emergencia (ERE), otros habían creado una estructura similar educación a distancia (EAD). Estas adaptaciones habían generado otros dilemas sobre como sería la esseñanza y, por tanto, lo que sería evaluar en estos modelos de la educación. Este trabajo informa la experiencia de la evaluación con tres turmas de segundo grado, en la escuela SESC de Ensino Médio (ESEM), que adoptara ERE, de una situación de problema, estruturada en el ambiente de aprender con referencias a la realidad. El modelo usado era una investigación, ése tenía como objetivo promover una reflexión más grande y entender en la importancia del uso de la función exponencial en el análisis del comportamiento de la infección para el virus. Los estudiantes tenían eso para explicar la diferencia entre las funciones exponenciales, lineares y cuadráticas, basado en las informacións matemáticas disponibles en un texto que debe ser accedido do por un link proveído. Por otra parte, tenían e acceso a otro material, para entender algunos conceptos relacionados con COVID 19, como el impuesto del mí infecta, velocidad de la transmisión, y como estos conceptos (o algunos de ellos) si relaciónese con el modelo matemático estudiado, la función exponencial. Usando estas producciones, las respuestas de las 45 pupilas en lo referente a aprender de funciones exponenciales habían sido categorizadas y analizadas. Esta experiencia indica que es posible ampliar el proceso de la evaluación usando las tecnologías digitales.

Palavras-Clave: Evaluación. Educación remota. Función exponencial.

\section{Introdução}

O ano de 2020 tem sido muito diferente para todos. Com a pandemia do COVID-19, as aulas foram suspensas, o comércio, cinemas e teatros fecharam e todos tiveram que fazer isolamento, para prevenir o contágio. No Brasil e no mundo, diante dessa situação peculiar, muitas escolas tiveram que adotar um modelo que atendesse ao isolamento social e que permitisse a continuidade das aulas. Essa mudança colocou os professores, alunos e suas 


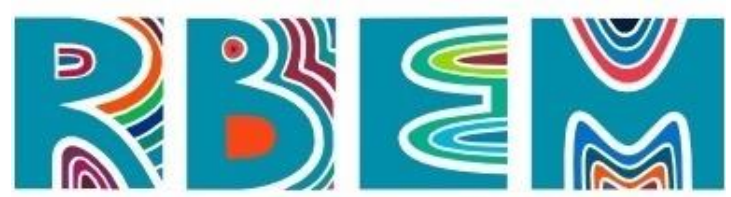

REVISTA BAIANA DE EDUCAÇÃO MATEMÁTICA

famílias diante de uma situação ímpar, procurando reposicionar o modelo de ensino presencial para um modelo de ensino a distância. Diante disso, muitas escolas adotaram o Ensino Remoto Emergencial (ERE), outras criaram uma estrutura similar ao ensino a distância (EAD). Esta mudança trouxe outros dilemas sobre como seria o ensino e, consequentemente, como seria avaliar neste momento. No Brasil houve um aumento significativo de lives nas redes sociais sobre a situação do ensino, da aprendizagem e da avaliação para ampliação do debate sobre como a escola, os professores, os alunos e as famílias poderiam lidar com a situação.

A partir desse cenário foi pensando em como avaliar durante a pandemia. Assim, este trabalho apresenta uma análise de conteúdo, do tipo categorial, de uma avaliação inovadora e que rompeu com o paradigma da pedagogia por objetivos. Além disso, essa experiência revela que é possível construir um modelo avaliativo que utilize dados reais, valorizar a atividade investigativa da avaliação e proporcionar o desenvolvimento de processos mais complexos de pensamento dos alunos utilizando a resolução de problemas, análise, interpretação e apresentação de dados ou a realização de experiências de natureza diversa.

Uma versão resumida deste trabalho foi apresentada no IX Seminário de Pesquisa em

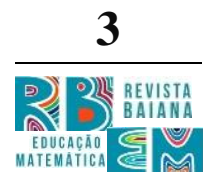
Educação Matemática do Rio de Janeiro (IX SPEM-RJ), realizado na modalidade virtual em dezembro de 2020. O artigo relata a experiência investigativa de avaliação adotada na Escola SESC de Ensino Médio (ESEM) durante o $1^{\mathrm{o}}$ semestre do ERE, que com três turmas da $2^{\mathrm{a}}$ série do ensino médio, a partir de uma situação problema. A atividade avaliativa constou da proposta de uma resolução de problema, a partir dos dados da Pandemia da Covid-19, dialogando com os conceitos que envolvem o ensino de função exponencial.

Além dessa versão resumida, foi apresentado, de modo virtual, um outro trabalho no Encontro Internacional a Voz dos Professores de Ciência e Tecnologia, de Portugal, em novembro de 2020, que também categorizou outra etapa dessa avaliação, a Etapa 3.

Este relato segue a seguinte sequência: referencial teórico, metodologia e considerações finais. O referencial teórico traz uma discussão sobre como os professores de Matemática avaliam e qual é o paradigma que dá suporte a essas práticas. Apresenta quais são as funções da avaliação, os motivos para pensar e fazer uma avaliação insubordinada, algumas 


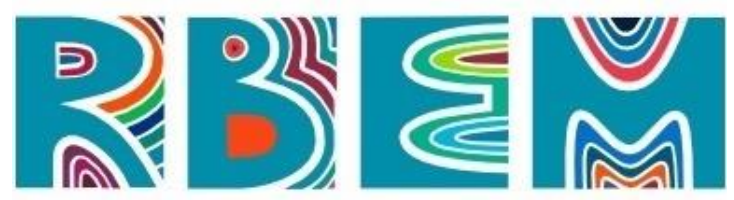

REVISTA BAIANA DE EDUCAÇÃO MATEMÁTICA

abordagens diferentes de ensino, a relação da avaliação com o currículo e os conceitos que definem a Análise de Conteúdo, adotada como o quadro teórico da análise das repostas.

A metodologia apresenta os dados do local onde foi realizada essa avaliação, a Escola SESC de Ensino Médio, a estrutura da avaliação que foi composta por três etapas e teve duração de 7 dias, a categorização das respostas dos alunos de uma das etapas e a análise dessas categorizações. Já as considerações finais apresentam quais foram as a ideias que emergiram após as análises e outros desafios.

\section{Referencial teórico}

Vaz e Nasser (2019) relatam que a avaliação escolar que se conhece hoje surgiu por volta do século XVII, e que talvez não seja tão adequada para as demandas atuais. Aliado a isso, pode-se refletir sobre as formas de aprender e ensinar: será que elas atendem às demandas atuais?

O modelo de avaliação que os professores de matemática mais utilizam é a prova, individual e sem consulta. De acordo com Vaz e Nasser (2019), esta ideia se baseia na filosofia positivista que está alicerçada na neutralidade e imparcialidade. Méndez (2002) configura esse modelo como a pedagogia por objetivos, que consiste na

interpretação e aplicação linear do condutismo ao currículo, que reduz o conhecimento a uma lista de objetivos empiricamente observáveis. O conhecimento equivale aos fatos, ao dado empírico, pois é considerado como algo dado, e o currículo resume-se em uma série de programações em torno de objetivos (MÉNDEZ, 2002, p. 30).

As ações lineares sobre o currículo colocam a avaliação como apenas um momento de verificação da aprendizagem, que assume o formato de uma lista de conteúdos que devem ser observados ao final de um período. Ou seja, o docente apenas cumpre o programa prescrito pela rede escolar e utiliza somente a função somativa da avaliação, que serve apenas para classificar os alunos de várias formas: por meio de notas ou menções; quando são agrupados por nível de aprendizagem, para a constituição de turmas; quando são rotulados em fortes, médios e fracos (VILLAS BOAS, 2006). 


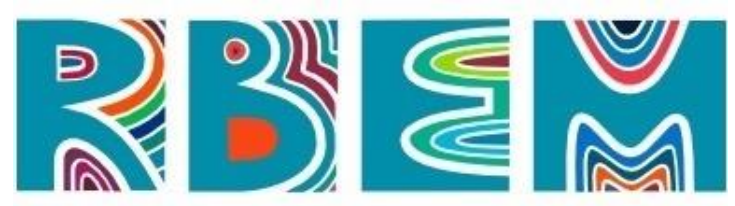

REVISTA BAIANA DE EDUCAÇÃO MATEMÁTICA

Junto a isso, a postura do professor encontra-se alicerçada na observação empírica das suas turmas, ou seja, o docente tenta controlar experimental e externamente o sujeito que aprende e também o seu desenvolvimento. Além de tentar prever os possíveis resultados das suas classes, ao reduzir a aprendizagem a condutas observáveis, inibindo a natureza exploratória dos processos de ensino e aprendizagem.

Essa estrutura que compõe as avaliações em matemática foi disseminada ao longo dos anos e do sistema escolar (VILAS BOAS, 2006). Segundo Fernandes (2008), mesmo com a expansão do ensino básico, não ocorreu uma mudança significativa nos currículos. Apesar da sua importância,

ainda não foi possível garantir que o fundamental do currículo fosse o desenvolvimento dos processos mais complexos de pensamento dos alunos mediante a resolução de problemas, análise, interpretação e apresentação de dados ou da realização de experiências de natureza diversa. (FERNANDES, 2008, p.20)

Amante e Oliveira (2016, p. 1) afirmam que a "avaliação é um processo central no ensino e é através da avaliação que o professor pode perceber se a trajetória por ele desenhada resulta na aprendizagem pretendida". Mas as avaliações e o que avaliam passaram a ser o

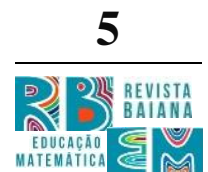
currículo oficial imposto às escolas. Dentro do sistema escolar, o currículo é o núcleo central e estruturante da função da escola (ARROYO, 2013). A partir deste ponto, pode-se inferir que avaliação se relaciona fortemente com o currículo. E mesmo com a universalização do ensino, não ocorreu alteração significativa na estrutura curricular, que poderia impactar na qualidade da avaliação. Esta mantém a estrutura focada na memorização, não permitindo novas formas de pensar e aplicá-la.

Méndez (2002) afirma que é preciso buscar formas novas e ousadas de avaliar, enquanto Skovsmose (2000) sugere uma alteração nas abordagens de ensino e Fernandes (2008) diz que os processos mais complexos de pensamento dos alunos mediante a resolução de problemas, análise, interpretação e apresentação de dados ou da realização de experiências são demandas do tempo atual. Unindo as propostas desses três autores, pode-se buscar um novo caminho para pensar e fazer a avaliação. 


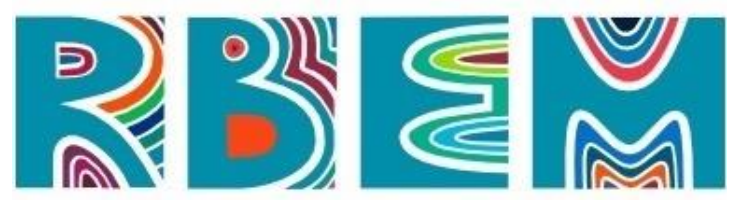

REVISTA BAIANA DE EDUCAÇÃO MATEMÁTICA

Como as aulas de Matemática são alicerçadas no paradigma do exercício, segundo Skovsmose (2002), a mudança do tipo de aula envolve uma mudança de paradigma. O autor sugere a mudança em direção a um modelo diferente, como, por exemplo, o cenário para investigação, que pode engajar os alunos ativamente em seus processos de aprendizagem. Ele afirma que um cenário para investigação é aquele que convida os alunos a formularem questões e procurarem explicações. As práticas de sala de aula baseadas num cenário para investigação diferem fortemente daquelas baseadas em exercício. A diferença entre elas tem a ver com as "referências" que visam levar os estudantes a produzirem significados para os conceitos e atividades matemáticas. O autor descreve assim os três tipos de referências:

questões e atividades matemáticas podem se referir à matemática e somente a ela, referência à Matemática Pura. Segundo é possível se referir a uma semirrealidade - não se trata de uma realidade que "de fato" observamos, mas uma realidade construída, por exemplo, por um autor de um livro didático de matemática. Finalmente, alunos e professores podem trabalhar com tarefas com referências a situações da vida real. (SKOVSMOSE, 2000, p.7-8)

A abordagem mais comum nas salas de aula recai na referência à Matemática Pura, embora ainda haja um esforço para tratar sobre a semirrealidade, em grande parte dos livrostextos. Porém, a discussão sobre referência a situações da vida real torna-se um desafio para o trabalho docente. De fato, levar as turmas a discussões sobre como, porque e para que a Matemática pode ser aplicada no cotidiano ou em outras ciências pode levar a um tratamento diferenciado do ensino de Matemática na escola básica.

Jürgensen $(2017$, p. 27) relata que uma das características do cenário de investigação “é que ele representa uma estrada pavimentada por incertezas e resultados imprevisíveis, repleta de riscos e possibilidades". O cenário para investigação com referência à matemática pura possibilita o desenvolvimento de habilidades que tratam do próprio saber matemático. Já o cenário para investigação com referências à realidade possibilita o desenvolvimento de habilidades matemáticas dentro das tarefas relacionadas a situações da vida real. Isso possibilita o desenvolvimento da Materacia, que segundo Skovsmose (2000, p. 1), "não se refere apenas às habilidades matemáticas, mas também à competência de interpretar e agir numa situação social e política estruturada pela matemática”. 


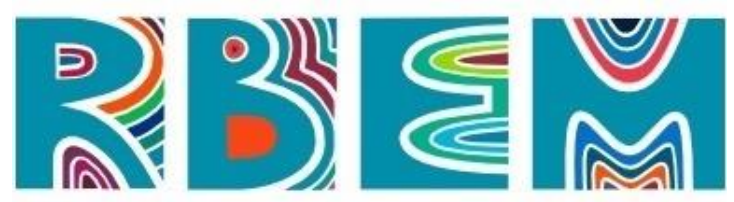

REVISTA BAIANA DE EDUCAÇÃO MATEMÁTICA

Portanto, reconfigurar o ensino da disciplina implica, então, em reconfigurar as formas de avaliação, buscando, assim, formas mais humanas e formativas.Essa reconfiguração se aproxima do conceito de avaliação insubordinada, definida como

toda avaliação que rompe, ou tenta romper, o absolutismo burocrático presente nas avaliações ou questionamentos as concepções positivistas que sustentam o modelo avaliativo tradicional. Consideramos avaliação insubordinada a avaliação que se constrói sobre a autonomia do professor, assumindo e redefinindo o seu papel de mediador da aprendizagem (NASSER, LIMA, et al., 2019, p. 115).

Diante do contexto atual, com aulas no ERE, surge a necessidade de alterar os processos de ensino, assim como construir, em um curto espaço de tempo, uma avaliação que fosse mais atual, que respondesse ao momento que as escolas estão passando. Isso possibilitou uma aplicação dos cenários para a investigação com referências à Matemática Pura e com referências à realidade, e, por conseguinte, o uso da Materacia.

Assim, este trabalho tem por objetivo apresentar uma análise das respostas dos alunos, como parte de uma avaliação que consolidasse as ideias de Mendez (2002), Fernandes (2008) e Skovsmose (2000). É usada uma técnica que segue a metodologia da Análise de Conteúdo, que Bardin define como

um conjunto de técnicas de análise de comunicações visando obter por procedimentos sistemáticos e objetivos de descrição do conteúdo das mensagens indicadores (quantitativos ou não) que permitam a inferência de conhecimentos relativos às condições de produção/recepção (variáveis inferidas) destas mensagens. (BARDIN, 2009, p. 44)

De acordo com Bardin (2009), a análise categorial consiste no desmembramento do texto em categoriais agrupadas analogicamente. Geralmente as categorias terminais provêm do reagrupamento progressivo de categorias com uma generalidade mais fraca.

Segundo Esteves (2006), a análise de conteúdo é a expressão genérica utilizada para designar um conjunto de técnicas possíveis para tratamento de informação previamente recolhida. A análise de conteúdo organiza-se em torno de três polos cronológicos: a préanálise, a exploração do material e o tratamento dos resultados, incluindo inferência e a interpretação (BARDIN, 2016, p.125).

A pré-análise consiste no trabalho de organização das ideias iniciais, de maneira que se tornem sistematizadas e operacionais, com um programa flexível (com uso ou não do 


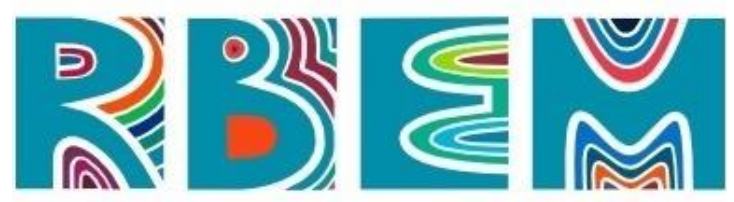

REVISTA BAIANA DE EDUCAÇÃO MATEMÁTICA

computador), que permita a introdução de novos procedimentos no decurso da análise, devendo ser, embora flexível, precisa. É na fase da leitura flutuante que são escolhidos os documentos que serão analisados, que se dá a constituição do corpus e a preparação do material propriamente dito, além da formação das hipóteses e dos objetivos e da elaboração de indicadores que fundamentem a interpretação final (MENDES e MISKULIN, 2017).

A leitura flutuante é a primeira atividade, que consiste em estabelecer contato com os documentos a serem analisados, em conhecer o texto deixando-se invadir por impressões e orientações. A escolha de documentos pode ser a priori ou posteriori. O corpus é o conjunto dos documentos considerados para serem submetidos aos procedimentos analíticos que seguem as seguintes regras, de acordo com Bardin (2016): regra da exaustividade, regra da representatividade, regra da homogeneidade e regra de pertinência.

A formulação das hipóteses está relacionada a uma suposição cuja origem é a intuição e que permanece em suspenso enquanto não for submetida à prova de dados seguros. No entanto, nem sempre são estabelecidas na pré-análise e tampouco é obrigatório ter-se como guia um corpus de hipóteses para proceder à análise (SERAFIM e VALTER, 2017).

De acordo com Bardin (2016), a referenciação dos índices e elaboração dos indicadores está relacionada à relação da manifestação dos indicadores que a análise dos textos explicitará. Já a preparação do material consiste em uma preparação formal dos textos antes da análise propriamente dita.

$\mathrm{Na}$ fase de exploração do material, ocorre a aplicação sistemática, manual ou informatizada, das decisões tomadas na pré-análise. Esta fase consiste, fundamentalmente, em operações de codificação, decomposição ou enumeração, em função das regras previamente estabelecidas. Nessa fase, o corpus estabelecido deverá ser estudado mais profundamente, com o objetivo de estabelecer as unidades de registro e unidades de contexto. Unidade de registro é a menor parte do conteúdo, na qual se entende qual é o elemento a se codificar, a classificar (ESTEVES, 2006). Bardin (2016) a apresenta como a unidade de significação codificada e corresponde ao segmento de conteúdo considerado unidade de base, visando à categorização e à contagem frequencial. Ela ainda apresenta as unidades de registro mais utilizadas: palavras, temas, objetos, personagens, o acontecimento e o documento, além de enfatizar que o critério da categorização é sempre de ordem semântica. 


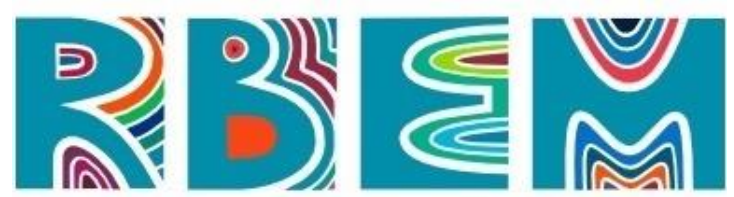

REVISTA BAIANA DE EDUCAÇÃO MATEMÁTICA

O tratamento dos resultados apresentado por Bardin (2016) consiste na categorização, descrição dos dados, análise dos dados, inferências e interpretações. Nessa fase ocorrem as análises para que os dados sejam significativos e válidos. As provas estatísticas e os testes de validação permitem um rigor mais aprimorado, o que propicia à pesquisa propor inferências e adiantar interpretações relacionadas com os objetivos previstos e outras descobertas que emergiram ao longo do estudo (BARDIN, 2016). De acordo com Vala (1986), a finalidade da análise de conteúdo está em realizar inferências com base em uma lógica explicitada. E deve seguir os princípios de exclusão mútua, homogeneidade, pertinência, objetividade, fidelidade e produtividade.

\section{Metodologia}

A Escola SESC de Ensino Médio (ESEM) fica localizada no bairro de Jacarepaguá, na cidade do Rio de Janeiro, Brasil, onde recebe alunos de todo o país, totalizando 165 alunos por série e cada turma possui 15 alunos. Configura-se como uma escola mista, de regime integral, pois aos alunos que não residem no estado no Rio de Janeiro são residentes. E também moram, atualmente com os alunos,15 docentes. A ESEM é uma instituição privada com carater público, portanto, todo o seu corpo discente é bolsista integral, ou seja, estadia, alimentação, cuidados médicos são custeados pela própria escola. Também se destaca o fato de que todos os alunos recebem um notebook ao ingressarem na $1^{\mathrm{a}}$ série. Diante da pandemia da Covid-19, o corpo gestor decidiu que todos os alunos deveriam retornar para suas casas, junto às famílias, e que o ano letivo seria conduzido pelo ensino remoto emergencial (ERE).

Antes da pandemia, a ESEM já utilizava ambientes virtuais de aprendizagem, como o Moodle, Teams e o Google Classroom, o que de fato facilitou a adaptação inicial do corpo docente aos novos modelos de ensino, aprendizagem e avaliação. Porém, a escola optou por construir o próprio conteúdo, utilizando a plataforma Moodle. E decidiu-se pela gravação de aulas e compartilhamento de material online, para que os alunos pudessem estudar no melhor tempo para eles, o que pode ser configurado como um modelo de EAD, segundo Vicente (2002). Nessas condições, o cenário indica que os alunos teriam condições de continuar seus estudos mesmo afastados da escola, e o corpo docente ficou com o desafio de avaliar a aprendizagem nesse modelo de ensino. 


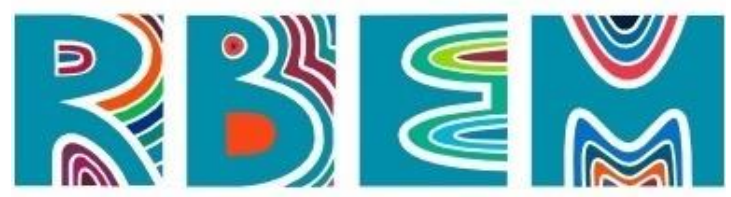

REVISTA BAIANA DE EDUCAÇÃO MATEMÁTICA

O primeiro conteúdo abordado nesse modelo, na $2^{\mathrm{a}}$ série do Ensino Médio, foi Função Exponencial, o qual proporcionou aos professores de matemática possibilidades de ousar na avaliação. A ideia central era construir um modelo de avaliação que permitisse uma discussão mais ampla sobre função exponencial e sobre o papel social da Matemática. Após três semanas de debates, entre a equipe de Matemática da $2^{\mathrm{a}}$ série, o modelo consolidado foi uma pesquisa, que tinha como objetivo promover uma maior reflexão e compreensão sobre a importância da aplicação da função exponencial na análise do comportamento da infecção pelo vírus. Estariam envolvidos outros conceitos também matemáticos na fundamentação científica das medidas de prevenção que podem e devem ser tomadas pelos indivíduos, pela sociedade em geral e governantes, segundo a OMS (Organização Mundial da Saúde).

Ao propor esta avaliação, buscou-se evidenciar a Materacia. Este instrumento de avaliação consistia em 3 etapas, e teve a duração de 7 dias: ORIENTAÇÃO PARA O TRABALHO DE PESQUISA, PESQUISA e CONCLUSÕES. Cada etapa tinha a sua orientação, como descrito a seguir, mas este trabalho será restrito à análise da Etapa 1.

\section{- Etapa 1: ORIENTAÇÃO PARA O TRABALHO DE PESQUISA}

$\mathrm{Na}$ etapa inicial, o aluno tinha que explicar a diferença entre as funções exponencial, linear e quadrática. Para isso, deveria recolher informações de cunho matemático disponíveis no link a seguir: <encurtador.com.br/EKPZ0>. A atividade 2 desta etapa era uma pesquisa sobre alguns conceitos que aparecem insistentemente e são imprescindíveis para o melhor entendimento da situação sobre a pandemia da covid-19. Por exemplo, $\mathrm{R}_{0}$, taxa de contágio, velocidade de transmissão, e como esses conceitos (ou alguns deles) se relacionam com o modelo matemático estudado, a Função Exponencial. A pesquisa deveria ser feita no link: <encurtador.com.br/xKRUW>.

- Etapa 2: PESQUISA

Consistia na comparação do comportamento da curva no Brasil com outro país, através do dashboard sobre a Covid-19, construído pela Universidade Johns Hopkins.

\section{- Etapa 3: CONCLUSÕES}

Após realizar as etapas anteriores, era preciso responder à pergunta central desta avaliação: “Como a Matemática pode contribuir para o combate à pandemia do Covid-19?" 


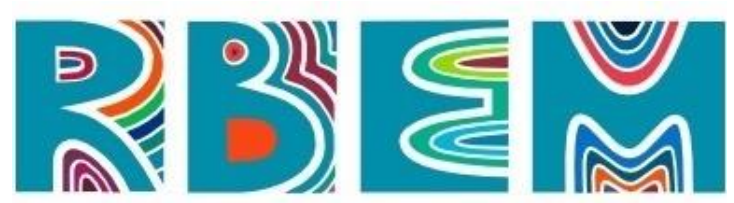

REVISTA BAIANA DE EDUCAÇÃO MATEMÁtICA

\section{Análise dos dados}

A análise de dados seguiu a estrutura apresentada na Teoria da Análise de Conteúdo. A pré-análise foi desenvolvida a partir das leituras dos trabalhos de todos os alunos, com foco principal na Etapa 1. Portanto, a escolha dos documentos ocorreu de forma a priori e constitui o corpus que foi analisado.

Além disso, todas as regras colocadas por Bardin(2016) como orientação na escolha dos documentos foram seguidas. A escolha de todos os trabalhos das três turmas contempla as regras de exaustividade e representatividade, pois são as turmas em que o professor atua no ERE. A escolha da Etapa 1 para ser analisada está de acordo com as regras de homogeneidade e de pertinência. Isso é garantido pelo fato de que todos os documentos seguem o mesmo critério de escolha, investigar a produção dos alunos a partir de uma situação problema. A regra de pertinência é satisfeita a partir do objetivo dessa análise, a categorização das respostas dos alunos para evidenciar a Materacia, que segundo Skovsmose (2000, p. 1), "não se refere apenas às habilidades matemáticas, mas também à competência de interpretar e agir numa situação social e política estruturada pela matemática”.

A formulação das hipóteses passou pelo objetivo dessa pesquisa: a partir da categorização das respostas dos alunos em relação à aprendizagem de funções exponenciais, foi possível evidenciar o conceito de Materacia, suportada pelos trabalhos de Skovsmose (2000), Fernandes (2008) e Méndez (2002).

$\mathrm{Na}$ fase de exploração do material, ocorre a aplicação sistemática e informatizada das decisões tomadas na pré-análise. Utilizando o software WebQDA como ferramenta de codificação e enumeração, as respostas dadas pelos alunos, nas Atividades 1 e 2 da Etapa 1 comporiam as unidades de contexto, que representam um segmento da mensagem mais lato do que a unidade de registro. Esteves (2006) diz que pode- se considerar como unidade de contexto a frase de um parágrafo e até entrevistas, desde que permitam compreender o sentido de cada uma das unidades de registro. Portanto, a escolha dessas atividades auxilia a compreensão das unidades de registro que foram selecionadas. O tema foi a unidade de registro escolhida, incluindo: as características de uma função exponencial, diferenças entre as funções afim, quadrática e exponencial e aplicações das funções quadrática, afim e exponencial. As unidades de registro foram escolhidas de acordo com o objetivo da pesquisa 


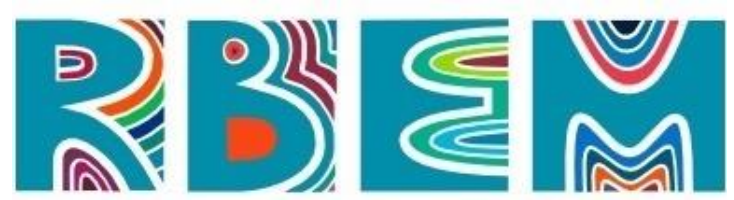

REVISTA BAIANA DE EDUCAÇÃO MATEMÁTICA

e com as produções dos alunos, possibilitando a criação dos seguintes temas: Materacia e Matemática Pura.

O tema Materacia foi divido em quatro categorias: aplicação da função linear, aplicação da função quadrática, aplicação da função exponencial e relação social da Matemática com a Covid-19. Cada categoria incluiu expressões que tinham o exemplo correlacionado de maneira correta como:

- Aplicação da Função Linear: "modelo de crescimento linear: aplicação de juros simples a um capital" - Aluno 1

- Aplicação da Função Quadrática: “função quadrática pode ser usada para calcular o lançamento e o movimento de projéteis como balas de canhão e foguetes." -Aluno 2

- Aplicação da Função Exponencial: “função exponencial é usada para determinar o crescimento de determinados seres vivos microscópicos, como as bactérias." Aluno 3

- Relação Social da Matemática com a Covid-19: “epidemias seguem um padrão matemático chamado função exponencial" - Aluno 4

O tema Matemática Pura foi divido em duas categorias: características da função exponencial e diferenças entre função linear, quadrática e exponencial. Foi adotado o mesmo procedimento utilizado nas outras categorias, como nos exemplos:

- Características de uma função exponencial: "Na função exponencial, você vai multiplicando o número por ele mesmo." - Aluno 5

- Diferenças entre função linear, quadrática e exponencial: “no modelo linear: o número anterior é somado e não multiplicando, ou seja, é um número fixo e constante (função linear). No modelo quadrático: quando os valores de seu resultado são fornecidos no quadrado do valor do seu argumento. (Função quadrática). No modelo exponencial: por um período sofre a multiplicação por uma constante, que inicia de forma gradual, mas que se acentua rapidamente. (Função exponencial)"- Aluno 6. 


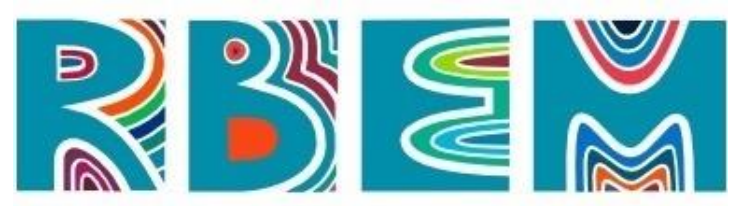

REVISTA BAIANA DE EDUCAÇÃO MATEMÁTICA

Segundo Bardin (2016), a análise qualitativa não rejeita qualquer informação de quantificação, pois o analista pode recorrer dos resultados para testes quantitativos. Assim, as categorias tiveram as frequências nas fontes utilizadas mostradas na tabela 1.

Tabela 1: Categorias identificadas na pesquisa

\begin{tabular}{lccc}
\hline \multicolumn{1}{c}{ Categoria } & Frequência & Fontes & Tema \\
\hline Características de uma função exponencial & 26 & 24 & Matemática Pura \\
$\begin{array}{l}\text { Diferençaentre Função Afim, Quadrática e } \\
\text { Função Exponencial }\end{array}$ & 19 & 19 & Matemática Pura \\
$\begin{array}{l}\text { Aplicação da Função Exponencial } \\
\text { Aplicação da Função Linear }\end{array}$ & 30 & 29 & Materacia \\
$\begin{array}{l}\text { Aplicação da Função Quadrática } \\
\text { Relação social da Matemática } \\
\text { Covid-19 }\end{array}$ & 23 & 23 & Materacia \\
\hline
\end{tabular}

Fonte: Autores.

A frequência refere-se à quantidade de vezes que a categoria surgiu e as fontes são os trabalhos dos alunos em que é citada. Os dados referentes às categorias mostram que nem todos os alunos conseguiram registrar, por meio das suas produções escritas, a relação social da Matemática com a Covid-19. Somente 35 fontes, das 45 disponíveis, fizeram menção a essa categoria. Todavia, o tema Materacia foi o mais evidenciado pelos alunos, revelando que a abordagem da avaliação possibilitou que os alunos estudassem situações em que as habilidades de Matemática têm um forte papel social. Há uma diferença muito pequena entre as categorias que envolvem as aplicações dos tipos de função, mas prevalecendo a função exponencial. Vale destacar que as unidades de registro dessa categoria não possuíam trechos que remetessem à Covid-19, justamente para cumprir com a regra de exclusão mútua.

As categorias relacionadas ao tema Matemática Pura foram as que tiveram uma menor frequência em relação ao todo. E a categoria que continha unidades de registro sobre as diferenças entre as funções teve o menor índice, mostrando que os alunos tiveram 


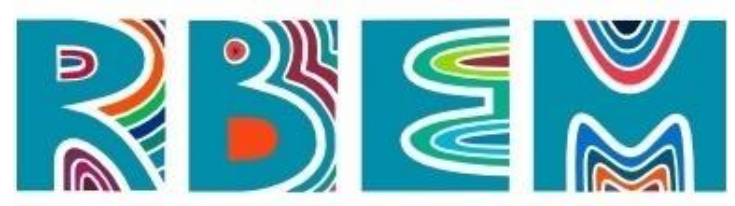

REVISTA BAIANA DE EDUCAÇÃO MATEMÁTICA

dificuldades de analisar as características das habilidades que tratam do campo da Matemática, nessa etapa da pesquisa.

As palavras que mais apareceram, seguindo a restrição de quantidade mínima de 5 caracteres e máxima de 20 caracteres estão registradas na tabela 2.

Tabela 2: Frequência das palavras mais usadas

\begin{tabular}{cc}
\hline Palavras & repetições \\
\hline função & 435 \\
exponencial & 385 \\
número & 294 \\
crescimento & 272 \\
tempo & 176 \\
\hline
\end{tabular}

Fonte: Autores.

Tanto a Tabela 2 como a Figura 1 mostram quais foram as palavras que mais apareceram nos trabalhos. E essas estão associadas ao estudo da função exponencial em tempos de Covid-19, reforçando que a Materacia foi um tema bem presente nas produções dos alunos.

Figura 1: Nuvem de palavras

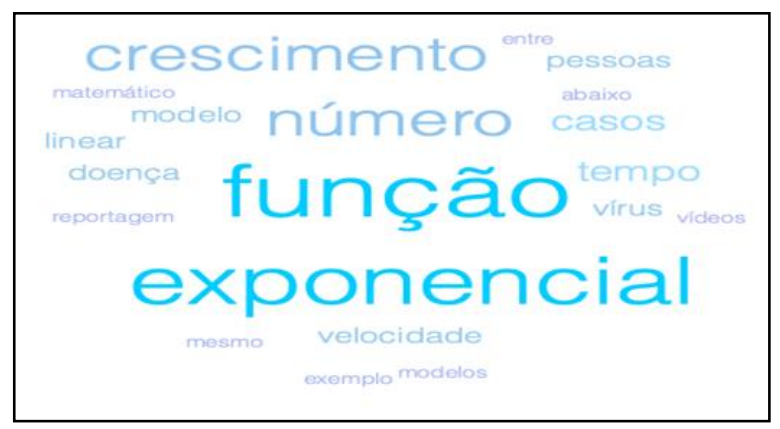

Fonte: Autores.

Outra análise foi feita, a partir das questões de gênero, como os meninos e as meninas construíram as suas percepções sobre a Materacia e a Matemática Pura. Andrade, Franco e Carvalho (2003) realizaram um estudo comparativo sobre o rendimento escolar entre alunos e alunas, explorando as diferenças em função de características socioeconômicas das populações ao atingir a $3^{\text {a }}$ série do Ensino Médio. Esses autores enfatizam que não desejavam expor qualquer tipo de predominância masculina e fragilidade feminina na aprendizagem. Do mesmo modo, este trabalho também não tem esse interesse, mas foi possível identificar quais 


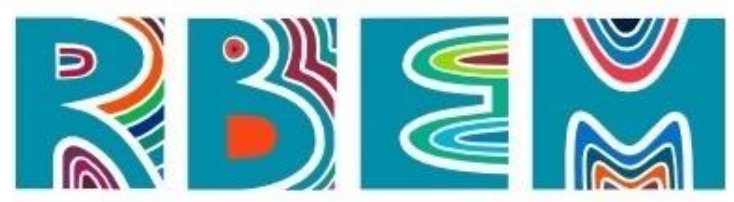

REVISTA BAIANA DE EDUCAÇÃO MATEMÁTICA

seriam as diferenças entre categorias das respostas dadas por gênero, conforme a tabela a seguir:

Tabela 3: Gênero x Categorias

\begin{tabular}{ccccccc}
\hline Gênero & $\begin{array}{c}\text { Características } \\
\text { de uma função } \\
\text { exponencial }\end{array}$ & $\begin{array}{c}\text { Diferença } \\
\text { entre Função } \\
\text { Afim, } \\
\text { Quadrática } \\
\text { Exponencial }\end{array}$ & $\begin{array}{c}\text { Aplicação da } \\
\text { Função } \\
\text { Exponencial }\end{array}$ & $\begin{array}{c}\text { Aplicação } \\
\text { da Função } \\
\text { Linear }\end{array}$ & $\begin{array}{c}\text { Aplicação } \\
\text { da Função } \\
\text { Quadrática }\end{array}$ & $\begin{array}{c}\text { Relação } \\
\text { social da } \\
\text { Matemática } \\
\text { e Covid-19 }\end{array}$ \\
\hline M & 13 & 12 & 18 & 14 & 14 & 42 \\
F & 13 & 7 & 12 & $\mathbf{9}$ & $\mathbf{1 0}$ & 21 \\
\hline
\end{tabular}

Fonte: Autores.

Ao analisar distribuição das categorias por gênero, percebe-se que os meninos apresentam uma frequência maior em quase todas as categorias, com exceção da categoria "características de uma função exponencial", em que houve empate nas frequências dos dois gêneros. O número total de meninos é de 23 e o número total de meninas é de 22 . Vale ressaltar que a Tabela 3 contabiliza a frequência total de cada categoria, ou seja, um aluno pode ter colocado mais de uma categoria em suas respostas. Porém, o número mínimo que se $\frac{15}{2 \text { OWE REVISTA }}$ esperava em cada categoria seria o equivalente de cada total:de meninos e de meninas.

Como a ESEM é uma escola nacional, que recebe alunos de todas as regiões do país, também foi possível separar a categorização por região. A distribuição dos alunos das três turmas observadas está registrada na tabela 4.

Tabela 4: Distribuição dos alunos por região do país.

\begin{tabular}{cc}
\hline Região do País & $\begin{array}{c}\text { Quantidade de } \\
\text { Alunos }\end{array}$ \\
\hline Nordeste & 11 \\
Sul & 11 \\
Norte & 6 \\
\hline Centro-Oeste & 6 \\
\hline Sudeste & 11 \\
\hline
\end{tabular}

Fonte: Autores. 


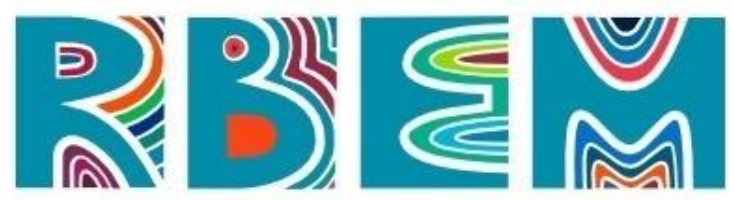

REVISTA BAIANA DE EDUCAÇÃO MATEMÁTICA

Pode-se observar que as regiões Norte e Centro-Oeste possuem um número menor de alunos, em relação às outras regiões. A tabela 5 apresenta a distribuição das categorias de acordo com a região do país.

Tabela 5: Região do país x Categorias

\begin{tabular}{|c|c|c|c|c|c|c|c|}
\hline $\begin{array}{c}\text { Região do } \\
\text { País }\end{array}$ & $\begin{array}{c}\text { Características } \\
\text { de uma função } \\
\text { exponencial }\end{array}$ & $\begin{array}{c}\text { Diferença } \\
\text { entre Função } \\
\text { Afim, } \\
\text { Quadrática e } \\
\text { Função } \\
\text { Exponencial }\end{array}$ & $\begin{array}{l}\text { Aplicação da } \\
\text { Função } \\
\text { Exponencial }\end{array}$ & $\begin{array}{c}\text { Aplicação } \\
\text { da Função } \\
\text { Linear }\end{array}$ & $\begin{array}{l}\text { Aplicação } \\
\text { da Função } \\
\text { Quadrática }\end{array}$ & $\begin{array}{c}\text { Relação } \\
\text { social da } \\
\text { Matemática } \\
\text { e Covid-19 }\end{array}$ & \\
\hline Nordeste & 6 & 4 & 6 & 6 & 6 & 17 & \\
\hline Sul & 7 & 4 & 9 & 5 & 9 & 10 & \\
\hline Norte & 5 & 5 & 2 & 3 & 2 & 9 & \\
\hline $\begin{array}{l}\text { Centro - } \\
\text { Oeste }\end{array}$ & 1 & 3 & 1 & 2 & $\mathbf{0}$ & 8 & \\
\hline Sudeste & 7 & 3 & 7 & 7 & 7 & 19 & 16 \\
\hline
\end{tabular}

Os alunos da região Centro-Oeste foram os que apresentaram as maiores dificuldades nessa etapa da avaliação. A tabela mostra que para os alunos dessa região, cada categoria teve uma frequência muito baixa, e em especial, a categoria "aplicação da função quadrática" não teve nenhum registro. Ao analisar a distribuição das categorias por região do país, pode-se perceber que a região sudeste foi a mais uniforme, em termos da frequência de cada categoria. E esperava-se que cada região tivesse, ao menos, o número mínimo de cada categoria na sua distribuição equivalente à distribuição da Tabela 4.

\section{Considerações Finais}

Esta proposta de avaliação confirmou que é possível construir uma proposta de avaliação insubordinada, que rompa com o paradigma da pedagogia por objetivos ao longo do processo do ERE. Méndez (2002) afirma que é preciso buscar formas diferentes e ousadas de avaliar, assim como Fernandes (2008) assevera que a interpretação dos resultados, a relação 


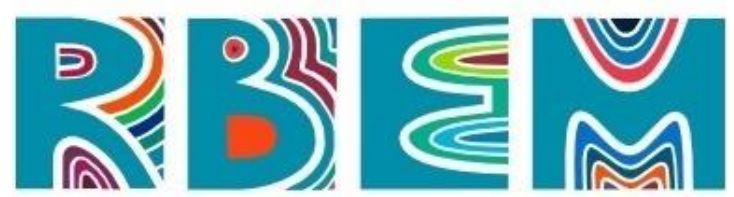

REVISTA BAIANA DE EDUCAÇÃO MATEMÁTICA

com outros conhecimentos adquiridos promove desenvolvimento de aprendizagens complexas. O modelo de avaliação discutido neste trabalho mostra-se como uma possibilidade de tal ação.

O trabalho apresentado pelos autores deste trabalho no Encontro Internacional a Voz dos Professores de Ciência e Tecnologia, de Portugal, em novembro de 2020, também teve como objetivo analisar os conteúdos das respostas elaboradas pelos alunos, a partir de uma avaliação que não segue os moldes tradicionais. , o foco estava na Etapa 3, na qual os alunos deveriam responder à seguinte pergunta:“Como a Matemática pode contribuir para o combate à pandemia do Covid-19?". As categorizações possibilitaram entender que o modelo de avaliação apresentado se consolidou como um instrumento que possibilitou a contextualização da avaliação, pois demandou dos alunos leituras, análises de vídeos, análises de gráficos, uma aproximação com dados reais e despertou nos alunos a consciência do papel social da Matemática.

Ao analisar, no presente artigo, a Etapa 1 da avaliação, pode-se inferir que este instrumento foi de fato insubordinado e criativo. Os alunos e as alunas puderem construir outras habilidades, como análise de dados e gráficos, leitura e interpretação e uma escrita matemática diferente. O ERE mostrou -se bem desafiador tanto para os alunos, como para os professores. E ao elaborar uma proposta que utiliza o contexto em que estavam inseridos, permitiu aos alunos a aprendizagem dentro de um cenário para investigação, o que possibilitou uma outra mudança do paradigma, do uso exclusivo dos exercícios para o paradigma da análise e reflexão.

Optou-se por não incluir a análise da Etapa 2, na qual os alunos tiveram que pesquisar dados dos seus respectivos estados e compará-los com outros países, além de promover uma discussão e reflexão com as turmas sobre como a Pandemia afetou mais a população negra, em especial nos EUA, local onde esses dados estão disponíveis. Tal etapa também demandaria uma análise de conteúdo como essa que foi feita, e uma discussão de como os alunos entenderam e compararam os dados da Pandemia dos seus estados em relação a outros países. Uma outra investigação poderia ser a análise das três Etapas e identificar como os meninos e as meninas construíram seus argumentos, como os alunos de cada região registraram os dados dos seus estados. 


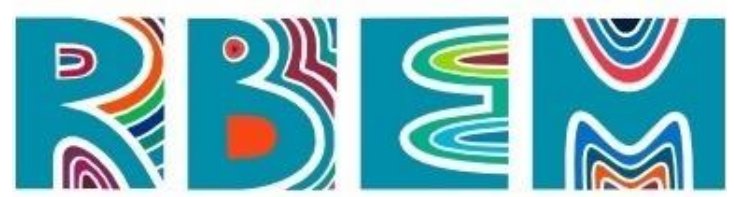

REVISTA BAIANA DE EDUCAÇÃO MATEMÁTICA

Este trabalho traz elementos para a exploração do estudo sobre avaliação dentro de cenários para investigação, ampliando o debate sobre o uso da avaliação durante o ERE. Além disso, o debate sobre quais são as concepções docentes e discentes sobre a avaliação em Matemática precisa ser ampliado, já que nesse modelo de ensino, ERE, muitos professores apenas transferiam suas práticas docentes da sala de aula presencial para o modelo remoto. E consequentemente, suas práticas avaliativas seguia o modelo tradicional. A avaliação tem um papel central no currículo (ARROYO, 2013) e precisa trazer os avanços e as demandas do tempo presente para as nossas salas de aula (FERNANDES, 2008). Ou seja, não podemos manter o mesmo sistema de avaliação e esperar resultados diferentes dentro do processo educativo. Assim, é importante destacar que a ausência do uso das tecnologias digitais e da internet nas avaliações é uma outra temática que precisa ser debatida, pois durante esse momento de pandemia, ficou evidente que o uso das tecnologias digitais para ensinar e avaliar pode ser ampliado. E este trabalho mostrou uma experiência indicando que é possível utilizar a internet como recurso para avaliação com bons resultados.

Portanto, espera-se que após esse momento de ERE as escolas, em especial os professores de Matemática permitam-se construir novos olhares sobre a avaliação em sala de aula, ampliando o seu uso formativo e promovendo um ensino mais democrático e inclusivo de Matemática nas escolas de todo o país. É preciso trazer a avaliação para o século XXI.

\section{Referências}

AMANTE, L; OLIVEIRA, I. Avaliação das Aprendizagens: Perspetivas, contextos e práticas.In: Amante, L; Oliveira, I. Avaliação das Aprendizagens: Perspetivas, contextos e práticas. Portugal: Universidade Aberta-LE@D, 2016. p 54-74.

ANDRADE, M.; FRANCO, C.; CARVALHO, J. B. P. Gênero e desempenho em matemática ao final do ensino médio: quais as relações?. In: Estudos em Avaliação Educacional, São Paulo, n. 27, jan./jun. 2003.

ARROYO, Miguel G. Currículo, território em disputa. Petrópolis, RJ: Vozes, 2013.

BARDIN, L. Análise de Conteúdo. Edição revista e atualizada. Lisboa: Edições 70, 2009.

BARDIN, L. Análise de Conteúdo. Edição revista e atualizada. Lisboa: Edições 70, 2016. 


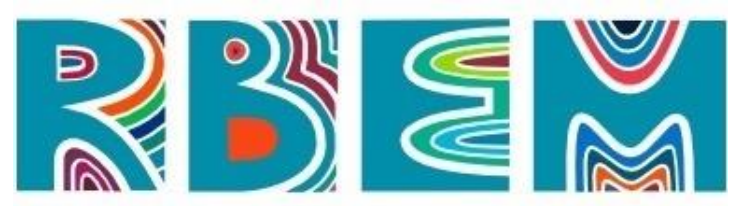

REVISTA BAIANA DE EDUCAÇÃO MATEMÁTICA

ESTEVES, Manuela. Análise de Conteúdo. In: LIMA, Jorge Ávila de; PACHECO, José Augusto (Orgs.). Fazer investigação: contributos para a elaboração de dissertações e teses. Porto: Porto Editora, 2006, p. 105-126.

FERNANDES, D. Avaliar para aprender: fundamentos, práticas e políticas. São Paulo: Editora Unesp. 2008.

JÜRGENSEN, Bruno Damien da Costa Paes. CENÁRIOS PARA INVESTIGAÇÃo COMO FERRAMENTA DE AVALIAÇÃO: UMA DISCUSSÃO. Educação Matemática em Revista, Brasília, v. 22, ed. 56, p. 21-38, out/dez 2017.

MÉNDEZ, Juan A. Avaliar para conhecer: examinar para excluir. Porto Alegre: Artmed. 2002.

MENDES, R. M.; MISKULIN, R. G. S. A Análise de Conteúdo como uma metodologia. Cadernos de pesquisa, São Paulo, v. 47, n. 165, p. 1044-1066, jul./set. 2017.

NASSER, L., LIMA, D., NOVÔA VAZ, R., et al."Discussing insubordinate practices in mathematics evaluation", International Journal for Research in Mathematics Education, p. 471-480, 2019.

SERAFIM, R. J., \&WALTER, S. A. O que Bardin diz que os autores não mostram? Estudo das produçõescientíficas brasileiras do período de 1997. Administração: ensino e pesquisa 18(2), pp. 241-269. 2017.

SKOVSMOSE, O. Cenários para investigação. Bolema, 14, 66-91. 2000.

VALA, J. A análise de conteúdo. In: SILVA, A. S.; PINTO, J. M. (Orgs.). Metodologia das ciências sociais. 8. ed. Porto: Afrontamento, 1986, p. 101-128.

VAZ, R. F. N..; NASSER, L. Em busca de uma avaliação mais "justa”. Com a Palavra o Professor, Vitória da Conquista (BA), v.4, n.10, setembro-dezembro, 2019.

VILAS BOAS, B. M. Avaliação formativa e formação de professores: ainda um desafio. Linhas Críticas, 2006 v. 12, n. 22, p. 75-90, 11.

Artigo submetido em: 15/11/2020

Artigo aceito em: 22/12/2020 